Murga, cuerpo y educación. Etnografía en una murga patagónica. Páginas 83-96 en Revista de la Escuela de Ciencias de la EduCACIÓN, AÑo 11, NúMERO 10, ENERO A DiCIEMBRE DE 2015. ISSN 1851-6297. ISSN EN Línea 2362-3349.

\title{
MURGA, CUERPO Y EDUCACIÓN. ETNOGRAFÍA EN UNA MURGA PATAGÓNICA
}

\author{
Por Pablo Marcelo Pena* \\ Universidad del Salvador, Argentina. \\ pablompena@gmail.com
}

Recibido: 26/06/2015 Aceptado: 15/09/2015

\section{Resumen}

A través del estudio etnográfico de una murga, se propone abrir posibilidades de análisis para describir, pensar y proyectar la construcción de trayectos contrahegemónicos en el ámbito de la producción artística y la educación. Caminos alternativos a la hora de pensar ciertos procesos sociales. Los modos de agrupamiento, la construcción de significados culturales sobre el cuerpo, y las formas (otras) de entender los fenómenos de enseñanza y aprendizaje son los ejes que atraviesan dicho análisis.

El artículo describe estos procesos en el marco del caso de una agrupación artística puntual; a la vez que señala algunas hipótesis de análisis con la intención de poder ser proyectadas en una dimensión más amplia, en el plano de lo social.

\section{Palabras clave:}

Cuerpo - Murga - Contrahegemonía - Enseñanza.

\section{Abstract}

Through ethnographic study of a murga, it aims to open analysis opportunities to describe, think and plan the construction of counter-hegemonic paths in the field of artistic production and education. Alternative ways to think certain social processes. Modes clustering, construction of cultural meanings on the body and forms (other) to understand phenomena of Teaching-Learning are the axis that go through this analysis.

* Musicoterapeuta (Universidad del Salvador). Auxiliar de docencia en diversas cátedras de la Facultad de Ciencias de la Educación, Universidad Nacional del Comahue. 
Revista de la Escuela de Ciencias de la Educación, año 11, número 10, enero a diciembre de 2015. PÁginas 83-96. ISSN 1851-6297. ISSN en LINEA 2362-3349. MURGA, CUERPO Y EdUCACIÓN. EtNografía EN UNA MURGa PATAGÓNICA. Pablo Marcelo Pena

Article describes these processes under the case of a particular artistic group; meanwhile analysis indicates some hypothesis with the intention of being projected towards a wider dimension in social terms.

\section{Keywords:}

Body - Murga - Counterhegemony - Education.

\section{Introducción}

La labor de investigación realizada, a través de métodos etnográficos, en el seno de una formación como la murga uruguaya "Lo Vecino" nos lleva al planteo de nudos de interrogantes en torno a los conceptos de cuerpo - poder - educación - arte - movimientos sociales.

Sostenemos que esta murga (y parece ser una tendencia en el ámbito de la murga y de otros movimientos artísticos como teatros independientes, agrupaciones de danza, arte callejero, etc.), al fundarse en objetivos contrahegemónicos, necesita construir una serie de mecanismos particulares de organización, subsistencia y crecimiento. Mecanismos que parecen no resultar de fácil construcción para las organizaciones, ya que sus bases desafían muchos de los elementos instalados como indiscutibles en la sociedad. Rompe convenciones, desafía conceptos y no se ata a las estructuras establecidas propuestas por el orden hegemónico.

Nos centramos aquí en esbozar una idea de cuerpo que necesita sostener la murga, a la vez que propone unas formas de educación allí donde las establecidas no pueden brindar respuestas.

A partir de ello nos preguntamos qué elementos podemos tomar de experiencias y procesos como éste a la hora de pensar la educación en términos contrahegemónicos. A la hora de seguir los caminos en la construcción social de la idea de "cuerpo", a la hora de pensar los recorridos alternativos de las agrupaciones artísticas.

\section{La investigación marco}

El presente artículo surge en el marco del proyecto de investigación que se realiza en la Facultad de Ciencias de la Educación de la UNCo (Universidad Nacional del Comahue). Desde mediados de 2013. Proyecto de investigación al que se suma luego, en asociación, la Facultad de Actividad Física y deporte de la UFLO (Universidad de Flores), sede Comahue. Bajo la dirección de Mag. Elias Rolando Schnaidler.

El proyecto se denomina: Estudio de las prácticas corporales, artísticas/recreativas, realizadas en instituciones y lugares de las ciudades de Neuquén/Cipolletti y Bariloche. 
Revista de la Escuela de Ciencias de la Educación, año 11, número 10, enero a diciembre de 2015. PÁginas 83-96.

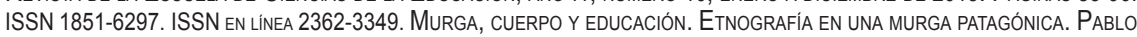
Marcelo Pena

Partimos del supuesto que algunos grupos, de conformaciones particulares, construyen y producen cultura de manera silenciosa y, a nuestro entender, no considerados en los marcos institucionalizados.

Es objeto de la investigación descubrir estos espacios, no valorados en el marco de la cultura hegemónica de las actividades corporales y de la generación de cultura en general, como verdaderos espacios alternativos de movimiento corporal, posibles anuncios de los nuevos modos por venir en nuestra cultura.

La propuesta de investigación consiste en indagar y analizar sobre aquellas prácticas corporales, enmarcadas en la categoría de "artísticas y recreativas" que adquieren características particulares en los ámbitos institucionales, en formaciones y lugares de producción de cultura: escuelas, escuelas de danza, clubes, centros comunitarios y espacios públicos urbanos, donde niños/as y jóvenes se agrupan y conforman diversos tipos de organización para el aprendizaje y la práctica de actividades corporales. Las mismas se constituyen en derredor de valores estéticos y recreativos, con algún grado de sistematización, dependiendo del lugar y ámbito de su realización, y que muestran formas de movimiento alternativos a los modelos hegemónicos conocidos, en la danza, el deporte y el juego" (Schnaidler, 2013, p. 8).

En esta investigación predominan los métodos etnográficos, ya que entendemos que esta modalidad habilita la posibilidad de bucear en la constitución de la perspectiva de los actores que realizan las prácticas. Las técnicas son enmarcadas en la utilización de entrevistas, observaciones y análisis de documentación y bibliografía.

La labor de campo se distribuye en una diversidad de grupos que tienen como vector la búsqueda estética. Grupos de teatro, danza, juego, acrobacia. En este caso, analizaremos, a partir de la labor etnográfica, una murga.

\section{La murga}

La murga, la murga uruguaya, esta murga en particular.

Es probable que podamos extraer aspectos comunes a cualquier conformación socialmente denominada "murga". Tambores, baile, la calle... Algo común, probablemente a todas la murgas: el escribir sus propios espectáculos, escribir las letras de las canciones. A veces componiendo la música, aunque generalmente tomando melodías prestadas. Pero siempre estableciendo los arreglos musicales (ya sean rítmicos o armónicos).

Al enfocarnos en el género denominado "murga uruguaya" esa lupa se acerca, y se resaltan aspectos mucho más específicos. Esencialmente el canto. Corporalmente parados. Levemente bailando. 
Revista de la Escuela de Ciencias de la Educación, año 11, número 10, enero a diciembre de 2015. PÁginas 83-96. ISSN 1851-6297. ISSN en LINEA 2362-3349. MURGA, CUERPO Y EdUCACIÓN. EtNografía EN UNA MURGa PATAGÓNICA. Pablo Marcelo Pena

Esta murga en particular eligió ser murga uruguaya, muy lejos del Uruguay, en la Patagonia. No tiene un arraigo territorial puntual y específico. Los sábados ensaya en una ciudad, los jueves en otra, y los miembros de la murga, dicen habitar en no menos de cinco ciudades distintas del Alto Valle. En sentido figurado podríamos jugar con la imagen de una murga semi-nómade, como los pueblos originarios del lugar. Una identidad fundada en la trashumancia.

"Entra otro integrante de la murga riéndose... En tono de chiste hace en gesto con las manos y viento con la boca. Evocando uno de esos arbustos que giran solos en el desierto. Señalando la poca asistencia de gente al ensayo" (Nota de campo № 1).

Las murgas en general parecen contener en sí un espíritu rebelde, ocupan espacios públicos destinados para otros fines, ocupan el silencio modificando la cotidianidad del lugar. En algunos casos esa rebeldía puede pensarse como contrahegemónica. Partimos del supuesto que quien se acerca a participar de una murga (cualquiera sea) puede estar motivado/a por razones como: incorporarse a un grupo social, bailar, cantar, expresarse... Sea cual sea el motivo, suponemos también, que la decisión de incorporación a la murga lleva consigo también cierta dosis de disconformidad con el estado actual de las cosas. La murga despliega la construcción de una parodia de la realidad, se ríe, se burla, desconoce las formas verticalistas de autoridad vigentes; y en ese momento muestra su "crítica" artera.

Para muchos, la murga puede ser sólo un lugar de paso, un conjunto de movimientos y sonidos sin sentido, quedando así desprovista de lo murguero, tan lleno de simbolismos. Pero muchos otros reconocemos este ámbito como un lugar de resistencia, "al lado del mundo oficial, un segundo mundo" (Bajtin, 2003, p. 11) de creación artística que pone en juego nuestra realidad y nuestra imaginación. "Soy murguero", decimos con orgullo en nuestras presentaciones personales; así nos identificamos (Abecasis, 2014).

Los orígenes del carnaval se describen como poner las relaciones de poder patas para arriba. Y quien ocupa los estratos más bajos de ese grupo social, por unos días, puede pasar a convertirse en rey.

Tomamos la cita del artículo de Luis Esteban Amaya: El Carnaval. Un viaje de identidades o antropología de la plenitud social, con el objeto de sintetizar esta particularidad política en el marco de la historia de la murga y del carnaval:

Como género contestatario el Carnaval sufrió censura siempre y casi siempre la eludió. Pero regó a la metáfora con reivindicación y resistencia. (...) La fiesta por excelencia de la contradicción y el desborde se vuelve rígida, una corporalidad institucionalizada, una creación artística para el escenario de un público receptor pasivo. 
Revista de la Escuela de Ciencias de la Educación, año 11, número 10, enero a diciembre de 2015. PÁginas 83-96. ISSN 1851-6297. ISSN en LINEA 2362-3349. MURGa, CUERPo Y EduCACIÓN. EtNografía en UNA MURGa PATAgÓnICA. Pablo Marcelo Pena

Lo mitológico y mágico que tiene el carnaval, la tendencia a la nivelación social, el desborde orgiástico, pone a prueba nuestro arraigado temor al caos. En lo que hace al comportamiento social, la transgresión se vuelve normalidad. El margen para la imaginación y la espontaneidad es tal que la comunidad no sólo admite los excesos, sino que los prohija. (...) Nuestra sociedad postindustrial, pretendidamente post-moderna y mundialmente mediatizada separa lo productivo de lo entretenido, la razón de la emoción (EI Corsito, 2003).

Al sumergirse en los sentidos históricos de la murga y el carnaval notamos como, a través de los siglos y de geografías de lo más amplias y diversas, no puede pensarse a la murga como movimiento artístico y social sino es con sentido contrahegemónico.

\section{Lo contrahegemónico}

Como señalábamos, es característica de la murga cierta dosis de disconformidad con el estado de las cosas. Y desde allí el ánimo de modificar la realidad, o al menos de parodiarla. Lo que podría pensarse como una forma de debilitar el poder vigente.

Referimos el concepto de hegemonía y su carácter dinámico en el marco de nuestra investigación:

(...) debe ser continuamente renovada, recreada, defendida y modificada. Asimismo, es continuamente resistida, limitada, alterada, desafiada por presiones que de ningún modo le son propias. Por tanto debemos agregar al concepto de hegemonía, los conceptos de contrahegemonía y de hegemonía alternativa, que son elementos reales y persistentes de la práctica (Williams, 2000, p.134).

La murga aparece como una organización difícil de controlar para los grupos que detentan el poder. Prueba de ello son las formas de prohibición y censura que desarrolló la dictadura militar argentina sobre las murgas, que fue de la mano de la anulación de los feriados a las fechas de carnaval.

¿Cómo se controla a una agrupación que no tiene sede fija?... que no se puede clausurar; que muchas veces no tiene un jefe o director visible; que se sustenta económicamente en forma solidaria y/o comunitaria con el aporte de los mismos integrantes o allegados; que no necesita habilitación municipal... Que aparece en una esquina y se expresa, que dice lo que no se puede decir en el corso, con máscaras y maquillajes, a resguardo gracias a la multitud.

Tomamos el siguiente relato respecto de la censura de las murgas en Uruguay en el marco de la dictadura militar. En el que por las características de concurso institucionalizado que adopta una de las formas del carnaval allí, 
Revista de la Escuela de Ciencias de la Educación, año 11, número 10, enero a diciembre de 2015. PÁginas 83-96. ISSN 1851-6297. ISSN en LINEA 2362-3349. MURGA, CUERPO Y EdUCACIÓN. EtNografía EN UNA MURGa PATAGÓNICA. Pablo Marcelo Pena

la censura cobra características especiales, y creemos que ilustra este ánimo de control que señaláramos:

(...) Carlos Prado consigna también: "un año -no me acuerdo el año- nos tacharon toda la letra. No concursamos, quedamos fuera de concurso. Salimos igual. Nos permitían salir pero íbamos en cana cada tres cuadras, te podrás imaginar. Eran los milicos los que te censuraban la letra". A pesar de la censura, señala Prado, el director de Diablos Verdes prefirió no modificar la letra y mantenerse al margen del concurso "salimos e hicimos lo que nosotros queríamos hacer, y cantamos lo que queríamos cantar. (...) No se corrigió la letra" (Graña Viñoly, Haronián Paraskevaídis, 2010).

La murga patagónica investigada aquí, la murga "Lo Vecino" del alto valle del río Negro, se ha organizado y ha accionado en sentidos contrahegemónicos. En principio señalamos la declarada autonomía de la murga, que refieren sus integrantes, respecto de: organismos estatales, partidos políticos, empresas; ni ninguna forma corporativa que pudiera generar influencia en sus expresiones artísticas o sus posicionamientos políticos.

Esta activa acción contrahegemónica se puede observar claramente analizando sus producciones artísticas y los eventos de los que han formado parte.

En una recopilación de información producto del sitio web de la murga en los últimos meses nos encontramos con la participación en las siguientes actividades:

- Participación en un disco regional patagónico con canciones dedicadas a niños y niñas de las escuelas y los barrios de Palestina.

- Marcha del 24 de marzo en la ciudad de Neuquén. Memoria, verdad y justicia.

- Visita a fábrica recuperada por sus trabajadores en organización cooperativa.

- Recital en una localidad del Alto Valle bajo la consigna: NO AL FRACKING!!!, NO AL BASURERO PETROLERO!! SI A LA CULTURA POPULAR!!! "... PORQUE LA CULTURA RESPIRA CON LA GENTE EN LA CALLE...”, LA MURGA ES PUEBLO.

- Recital, lema: “Una vez más LO VECINO murga cantamos a corazón abierto por el trabajo y la vida digna junto a nuestr@s compas de Cerámica Neuquén en lucha!!"

Contenido de sus letra y espectáculo:

Dice uno de los miembros de la murga en una nota periodística: "Lo que tratamos de transmitir es que la murga es protesta, la murga se queja, es pueblo y habla en nombre de los vecinos, de los que no tienen voz" (diario: La Mañana Neuquén - 4/7/2013). 
Revista de la Escuela de Ciencias de la Educación, año 11, número 10, enero a diciembre de 2015. PÁginas 83-96. ISSN 1851-6297. ISSN en LINEA 2362-3349. MURGa, CUERPo Y EduCACIÓN. EtNografía en UNA MURGa PATAgÓnICA. Pablo Marcelo Pena

En las letras de las canciones de autoría de la murga también aparece este ánimo de acción contrahegemónico:

"Con la dorada utopía del encuentro inquebrantable, irreductible, que nos retumba en la cabeza,

...para tratar de hacer un mundo mejor...

y en esta historia de desencuentro

en desencuentro que se escribe a cada paso,

...vamos haciendo un camino...

Un camino que es un medio,

...pero que también es el fin en sí mismo..."

(canción autoría de la murga 2013).

En otro tramo de la misma canción nos sorprende que además está especificada en los mismos términos conceptuales en la que se apoya nuestra investigación. Se habla directamente de "hegemonía":

"Por eso denunciamos y combatimos con todas nuestras fuerzas

el conjuro de las bestias del poder impuesto,

...de la hegemonía ostentada, ...de la verdad absoluta...

y de la opresión... que generando dolor buscan la rendición."

(canción autoría de la murga 2013).

En las notas y apariciones en los medios que realiza la murga siempre aparece la proclama de cierre: Murga es Pueblo!!!.

\section{Formas de organización}

En el marco de una de las observaciones realizadas en los ensayos de la murga surgieron entrevistas espontáneas, cosas que te cuentan mientras tenés el cuaderno en la mano con el ánimo de realizar un aporte a la investigación. En un tramo de ellas, escrita a modo de crónica, aparece claramente la explicación de las formas de organización vigentes en la murga:

(Uno de los integrantes de la murga) "Resaltó que la toma de decisiones en la murga se realiza en forma horizontal. A través de una asamblea cada dos meses. Pregunté acerca del rol del director de la murga (ya que había sido nombrado como tal en las charlas); y me pareció que podía contradecirse con la horizontalidad enunciada. A... fue contundente: El director solamente tiene funciones para dirigir lo musical" (Nota de campo $\mathrm{N}^{\circ} 2$ ).

Se concluye una relación directa entre la utopía proclamada y buscada y la propia forma de organización. Se optó por una metodología asamblearia que tendiera a disminuir las relaciones de poder de carácter verticalista. 
Revista de la Escuela de Ciencias de la Educación, año 11, número 10, enero a diciembre de 2015. PÁginas 83-96. ISSN 1851-6297. ISSN en LINEA 2362-3349. MURGa, CUERPo Y EdUCACIÓN. EtNografía en UNA MURGa PATAGÓNICA. Pablo Marcelo Pena

\section{El Cuerpo}

Luego de indagar en diversas propuestas respecto de la inclusión de la murga en ámbitos educativos, particularmente escolares. Nos encontramos con dos tendencias marcadas. En principio, se induce que surgen de ellos dos objetivos claramente distintos, y ella sería la principal diferencia. Pero sostenemos que de allí se derivan formas específicas y diferenciadas para entender: la murga, la educación, el cuerpo, la escuela.

La primera de las tendencias surge de entender la murga como mecanismo para incluir a los alumnos en la dinámica escolar, apuntando a sectores que por diversos motivos se encuentran marginados, no incluidos, al cotidiano escolar. Actitud inclusiva. La murga como herramienta para...

La segunda tendencia entiende a la murga como crítica a la lógica escolar, en el camino de subvertir las lógicas de poder instaladas, convencidas que son producto y reproducción de la lógica social. Actitud crítica. La murga como expresión artística y política.

Tomamos como ejemplo un proyecto de murga para el ámbito escolar en la República Oriental del Uruguay, que en la fundamentación de su proyecto dice:

"La murga promueve en los chicos actitudes de responsabilidad, de disciplina, compromiso y cooperación en el trabajo, al tiempo que se profundizan los vínculos afectivos y el sentido de pertenencia grupal e institucional' (Nota de campo $\mathrm{N}^{\circ} 3$ ).

Otro ejemplo, en este caso de la Argentina, surge de un proyecto de murga escolar en el ámbito de la educación especial. En los objetivos del proyecto se resalta:

"Favorecer en los alumnos las actitudes de responsabilidad, solidaridad, respeto y cuidado por sus producciones, posibilitando la convivencia democrática y la construcción de la ciudadanía" (Nota de campo № 4).

Los ejemplos aquí expuestos intentan ilustrar una tendencia que observamos habitualmente en el cruce de murga y educación. Considerando que las estructuras escolares poseen una dimensión casi monopólica de los procesos educativos, sociales y, sin ninguna duda, con una tendencia a representar y encarnar las posiciones hegemónicas en los sistemas políticos vigentes.

En ambos ejemplos se resalta el favorecer la responsabilidad como objetivo de la actividad murguística. Del primer ejemplo surge cooperación en el trabajo, pero esta cooperación, en las escuelas, se intenta establecer sin modificar las relaciones de poder de carácter verticalista, propios del común de las instituciones escolares. En el segundo caso se destaca el objetivo: construcción de la ciudadanía. No creemos que, en la motivación de los murguistas para acercarse a los ensayos, aparezcan fuertemente objetivos de estas características. 
Revista de la Escuela de Ciencias de la Educación, año 11, número 10, enero a diciembre de 2015. PÁginas 83-96. ISSN 1851-6297. ISSN en LINEA 2362-3349. MURGa, CUERPo Y EduCACIÓN. EtNografía en UNA MURGa PATAgÓnICA. Pablo Marcelo Pena

La idea aquí no es forzar una crítica aislada a diversas iniciativas murgueras tomadas por docentes de esta parte del mundo. Sencillamente se intenta ilustrar una tendencia, destacar un choque, lo que suponemos como un conflicto de intereses. Los objetivos sociales de la institución escolar y los de la murga, como forma de organización social y expresión de sectores de la cultura popular, apuntan a sentidos antagónicos. La escuela no tiene carnaval, no puede permitirse la sátira de sus autoridades, y mucho menos la movilidad de roles en su dinámica.

La murga (y particularmente la murga porteña) promueve un despliegue corporal de características expresivas de dimensiones exageradas. Saltos, patadas voladoras, suelo, contacto visual, improvisación; ocupando espacios no previstos para ello y en períodos de tiempo extensos. Baile que incluye -muchas veces en la práctica y sin dudas en sus orígenes- el ingreso a un cierto estado de catarsis.

Este no es el cuerpo que parece darse el permiso de ingreso a la escuela, de hecho parece poseer las características que la misma escuela sanciona, condiciona o evita.

En "La escuela en el cuerpo" sostienen Milstein y Mendez sobre la educación estética escolar: "Se trata de una forma de la educación moral, de la inculcación de las normas morales a través de los sentimientos experimentados ante lo bello" (Milstein y Mendez, 1999, p. 91).

A la vez que resaltan la distancia, la no correspondencia, entre la estética escolar y las expresiones artísticas: "Las convenciones de la estética escolar (...) no se corresponden con las del campo artístico sino con el arbitrario cultural escolar" (Milstein y Mendez, 1999, p. 95).

Encontramos en la murga investigada en este caso una postura distinta, una actitud crítica, por fuera de la lógica escolar. Es clara la intención de subvertir las lógicas de poder instaladas, convencidas que son producto y reproducción de la lógica social hegemónica. Es lo que lleva a esta murga a mantenerse por fuera de los caminos institucionales tradicionales (estatales y privados).

"A veces nos llamaban las maestras o las directoras para ir con la murga a la escuela. Nosotros, si podíamos ir, les decíamos que sí. Pero les pedíamos que la escuela salga, que tocábamos en la plaza de enfrente, en la esquina, en el salón comunitario del barrio... pero no en el salón de actos de la escuela. No tenía nada que ver. Por ahí, estábamos por tocar, y teníamos que esperar que la directora o una maestra se ponga a retar a los chicos. Y nosotros ahí parados, vestidos y maquillados. O estábamos terminando una canción y a alguien de la escuela se le ocurría tocar el timbre, porque era la hora, no por joder. Entonces los chicos se iban al patio, o no sabían que hacer" (Nota de campo $\mathrm{N}^{\circ} 5$ ). 
Revista de la Escuela de Ciencias de la Educación, año 11, número 10, enero a diciembre de 2015. PÁginas 83-96. ISSN 1851-6297. ISSN en LINEA 2362-3349. MURGA, CUERPO Y EdUCACIÓN. EtNografía EN UNA MURGa PATAGÓNICA. Pablo Marcelo Pena

\section{Educación}

¿Quién enseña? ¿Cómo se enseña?

El modo de enseñar, transmitir los conocimientos, organizar las formas musicales aparecen como un aspecto de interés. Que pone a prueba, contrasta e interpela, a ciertas formas naturalizadas socialmente sobre los fenómenos de enseñanza/aprendizaje.

Quien se acerca a participar de una murga probablemente "no sabe de murga", ni tampoco cree conscientemente que se acerca a un espacio específicamente de aprendizaje. Sin embargo creemos que son múltiples y centrales los fenómenos que se dan en esta línea. Y resulta interesante para la presente investigación describir las características de esos procesos. Probablemente porque en esos procesos se esconden muchos de los elementos que nos permitan afirmar que dicha práctica podría ser de carácter contrahegemónica.

Mostramos, a continuación, algunos ejemplos de momentos de la cotidianidad de la murga investigada aquí, que refieren acciones concretas de enseñar y/o aprender:

"Estábamos esperando el comienzo del ensayo. Mientras A me hablaba, $M$ escuchaba temas de murga uruguaya en una compu mientras sacaba los toques con los palillos, ya sea sobre un bombo, la mesa o el piso" (Nota de campo $\left.\mathrm{N}^{\circ} 6\right)$.

"El director saca la guitarra, la afina, y realizan un ejercicio de calentamiento de voces. El coro repite unas simples lineas melódicas que el director les muestra con la guitarra y su voz" (Nota de campo № 7 ).

"El director iba organizando las voces en torno a una canción, el saludo de la futura obra. Iba repasando la línea melódica en cada una de las tres voces por separado y posteriormente con las voces juntas. En repetidas oportunidades el director hacía una pausa, daba una indicación puntual del tipo: "Esa no es la nota, buscá un poco más arriba". O algunos de los cantantes se señalaban a sí mismos: "Me apuré, va de nuevo"." (Nota de campo № 8).

Las formas de escritura y transmisión de saberes cobran gran especificidad, encontrando códigos y mecanismos puntuales con el fin de conservar y divulgar dichos saberes; que son compartidos por los miembros de la murga.

"Me muestra como escriben las canciones. La información musical escrita circula de 3 formas diferentes: Sólo la letra, letra con cifrado para guitarra, letra con notas debajo de cada sílaba especificada por voz: sobreprimo, primo, segundos. Debajo de cada sílaba, un renglón para cada voz donde se escribe en letras: mi, sol, etc." (Nota de campo № 9).

Este mecanismo brinda la posibilidad de aprendizaje y guía en la lectura para quien no posee los conocimientos musicales propios de los ámbitos formales de educación musical (la lectura de un pentagrama). 
Revista de la Escuela de Ciencias de la Educación, año 11, número 10, enero a diciembre de 2015. Páginas 83-96. ISSN 1851-6297. ISSN en LINEA 2362-3349. MURGA, CUERPO Y EDUCACIÓN. EtNografia EN UNA MURGA PATAGÓNICA. PabLO Marcelo Pena

Sabemos que esta característica es habitual en los géneros llamados "populares", pero entendemos que en el caso de la murga uruguaya, la complejidad armónica en sus arreglos de voces, lleva a la necesidad de adoptar mecanismos más sofisticados de lo habitual en este aspecto. Tanto sea para el aprendizaje de la línea melódica del canto, de una de las voces, como en la organización de las distintas voces en los ensayos.

Las dudas o diferencias en la afinación de una nota que resultaran durante el ensayo, se observó que se definen siempre, en primera instancia, en forma auditiva a través de la entonación de la nota con la voz o el director musical con la guitarra. Pero sostenida la duda, se recurre al papel como resolución de la diferencia.

De todos modos, creemos que la principal importancia de esta forma de escritura tiene relación con la posibilidad de aprendizaje de cada línea melódica.

Hasta aquí, con estos ejemplos, podemos mostrar formas de aprendizaje de técnicas e información puntual necesaria para la participación en la formación y para la producción artística. Observamos formas autodidactas y mecanismos de circulación de saberes a través de medios orales y escritos.

Pero notamos que los procesos educativos en el interior de la murga exceden a la indispensable instancia de aprendizaje de letras, afinaciones, voces y ritmos. Mostramos a continuación otro momento en los ensayos de la murga:

"A propone primero una instancia de respiración/relajación, y luego un juego de ronda corporal. La consigna era "hacer pases de energía". Todos parados se hacía una especie de ola de gestos con la mano. Cada movimiento iba acompañado del sonido "zip", pero si se decía "zap" cambiaba el sentido de la ola. Luego se fue complejizando, y otros sonidos implicaban saltear a uno en la ronda o mandar "la energía" hacia el lado opuesto. Surgen risas cada vez que aparece un error y se vuelve a empezar, cobrando mayor velocidad a medida que transcurre el juego" (Nota de campo $\mathrm{N}^{\circ} 10$ ).

La inclusión de un juego de estas características es interpretada, en esta investigación, como una preocupación por aspectos más abstractos y menos instrumentales en los fenómenos educativos. La dinámica apuntaría a la convivencia, a resaltar la importancia de los vínculos al interior de la formación, mejorar la disposición al encuentro de los sujetos, e incluso una mejor disposición para la tarea. Lo que entendemos otorga un grado importante de complejidad a los procesos educativos al interior de la agrupación.

Encontramos aquí una relación directa con las formas horizontales de gobierno que procura sostener la murga como forma de organización (lo tratábamos cuando hablábamos de lo contrahegemónico), con los mecanismos no verticalistas de transmisión de saberes que se detallan aquí.

Parece claro que la murga evita el modelo de enseñanza-aprendizaje más conocido por los miembros y socialmente hegemónico: el modelo escolar. Y tiene la necesidad de construir otro. Para analizar las características de este 
Revista de la Escuela de Ciencias de la Educación, año 11, número 10, enero a diciembre de 2015. PÁginas 83-96. ISSN 1851-6297. ISSN en LINEA 2362-3349. MURGA, CUERPO Y EdUCACIÓN. EtNografía EN UNA MURGa PATAGÓNICA. Pablo Marcelo Pena

modelo traemos el desarrollo que realiza Marcela Ickowicz, quien plantea la contraposición de dos modelos educativos para explicar las características y el contraste de la formación en cátedras universitarias, en contraposición con el modelo escolar:

El modelo del artesanado medieval, constituyendo la experiencia misma la base del proceso de formación en la que el aprendizaje se encuentra estrechamente vinculado a la práctica del oficio. (...) El modelo escolar se caracteriza por separar en dos contextos diferenciados transmisión de saber y trabajo productivo, mientras que la enseñanza de los conocimientos se presenta codificado en disciplinas con lógicas y estructuras que les son propias y que han sido definidas con anterioridad al encuentro entre maestro y alumno, el trabajo productivo consiste en la demostración por parte del alumnos de esos saberes adquiridos a partir de diversos modos de control (Ickowicz, 2007).

No nos parece casual la existencia de similitudes entre la formación universitaria y los modos de enseñanza-aprendizaje en el interior de la murga. Probablemente, las características de autonomía de las universidades y las cátedras nos pueden llevar a encontrar ciertas similitudes en los modelos educativos en ambos. Que pueden prescindir de los procesos de producción y control propios del modelo escolar.

La dialoguicidad es el punto de partida de concebir la educación como práctica de la libertad. La relación entre educador-educando en la situación pedagógica se establece partiendo de los saberes que trae consigo el educando, y de los temas que forman parte de su cotidianeidad. Esta relación dialógica es también dialéctica, en el sentido de que la educación que se lleva a cabo es de A con B con la mediación del mundo. No imponer nuestra visión de mundo, sino dialogar con él acerca de su visión y la nuestra (Freire, 1970, p. 22).

Las palabras de Freire y las formas de concreción que encontró la murga "Lo Vecino" de llevar a cabo su propuesta artística, refuerzan la idea que resulta indispensable pensar los procesos educativos de la mano de los procesos políticos. Así, las aspiraciones contrahegemónicas, las formas de organización, y los métodos educativos parecen ir en búsqueda de una coherencia ideológica y metodológica.

\section{Conclusiones}

La murga "Lo vecino" muestra un recorrido donde, luego de posicionarse con claridad en lo político-ideológico, logra también situarse en un lugar sólido respecto de lo corporal. Despegándose de los modelos hegemónicos, 
Revista de la Escuela de Ciencias de la Educación, año 11, número 10, enero a diciembre de 2015. PÁginas 83-96. ISSN 1851-6297. ISSN en LINEA 2362-3349. MURGA, CUERPO Y EDUCACIÓN. ETNOGRAFIA EN UNA MURGa PATAGÓNICA. PablO Marcelo Pena

que identificamos aquí con la institución "escuela" como referente social en la construcción de una determinada idea de cuerpo.

Prestamos particular interés en las formas de enseñanza-aprendizaje logradas por esta formación. Interés en las maneras encontradas -a través de caminos alternativos- de responder a la necesidad de construir formas nuevas, distintas a las conocidas y que se muestran como las únicas, y que parecen no compatibles con la búsqueda artística y política de la murga.

La murga necesita perdurar y crecer. Para ello depende de formas eficientes de incorporar nuevos miembros y sostenerlos; de enseñar los saberes acumulados sin reproducir las formas sociales que critica y que busca modificar. A partir de lo observado en el campo entendemos que la murga encontró formas eficientes y coherentes de hacerlo. Y como lo señaláramos respecto de lo corporal, parece determinante que ante la necesidad de buscar y crear itinerarios específicos de enseñanza-aprendizaje, estos caminos se dieran por fuera de los modelos educativos tradicionales (modelo escolar).

Desarrollamos aquí un paralelismo con el artesanado medieval (Ickowicz 2007) como un modo de explicar esta forma de abordar lo educativo. Aunque estamos seguros que es una hipótesis más entre aquellas posibles; que nos pueden permitir comenzar a analizar los recursos en que, formaciones de estas características, logran desplegar una educación de sus saberes a través de caminos alternativos y contrahegemónicos.

En el convencimiento que, al desandar esos caminos, al estudiar sus características, podemos encontrar elementos fundamentales para construir a niveles sociales educación y arte por fuera de los mandatos de los mecanismos hegemónicos.

\section{Referencias Bibliográficas}

- $\quad$ Abecasis, J. E. (2014). "Murga y educación: El ingreso a la investigación de y desde una práctica cultural y participativa, el recorte del contexto, el recorte de la universidad, aportes para la inclusión de la alegría". Ponencia en: IV Jornadas Nacionales y II Latinoamericanas de Investigadores/as en Formación en Educación. 25, 26 y 27 de noviembre. Facultad de Filosofía y Letras. Universidad de Buenos Aires.

- $\quad$ Freire, P. (1970). Pedagogía del oprimido. Buenos Aires: Siglo XXI.

- Graña Viñoly, F. y Haronián Paraskevaídis, N. (2010) "Murgas en dictadura. Uruguay 1971-1974". Ponencia en: IX Jornadas de Investigación de la Facultad de Ciencias Sociales. Udelar, Montevideo, 13-15 de setiembre.

- Ickowicz, M. (2007). Las Cátedras universitarias: un espacio para la formación de los docentes. Rev. Actas Pedagógicas FCE-UNComahue. Número especial: Instituciones educativas.

- Milstein, D. y Méndez, H. (1999). La Escuela en el cuerpo. Estudios sobre el orden escolar y la construcción social de los alumnos en escuelas primarias. Buenos Aires: Miño y Dávila Editores. 
Revista de la Escuela de Ciencias de la Educación, año 11, número 10, enero a diciembre de 2015. PÁginas 83-96.

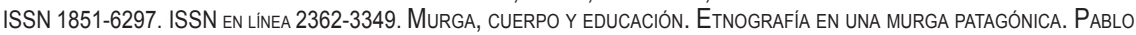
Marcelo Pena

- Schnaidler R. (Director) (2013). Estudio de las prácticas corporales, artísticas/recreativas, realizadas en instituciones y lugares de las ciudades de Neuquén/Cipolletti y Bariloche. Universidad Nacional del Comahue.

- $\quad$ Schnaidler, R. y otros. (2014). "Estudiando pequeños agrupamientos de prácticas corporales, que implican producción cultural, en las ciudades de Cipolletti, Bariloche y Neuquén. Sus ideas centrales y su abordaje metodológico". (Ponencia). FLACSO.

- Williams R. (2000). Marxismo y literatura. Barcelona: Ediciones Península.

\section{Revistas consultadas:}

- El Corsito. Año VIII. N 29. Año 2003. Publicación del Centro Cultural Rojas. UBA. Dirección: Coco Romero. 